\title{
Cashew Tree Bark Secretion - Persectives for its Use in Protein Isolation Strategies
}

\author{
Raquel Lima Miranda**\#
}

\author{
Lectins and Glycoconjugates Laboratory, Dept of Biochemistry and Molecular Biology Federal University of Ceara, \\ P.O. Box 6020, Fortaleza, Ceara, 60000, Brazil
}

\begin{abstract}
The use of natural gums, taken from the exudates and extracts of plants, has been given a strong impulse due to both the many and lucrative possibilities for industrialization and to the excellent international market. A gum or resin of a yellowish color, soluble in water, and which presents a great potential for industrialization, appears on the trunk and branches of the cashew tree; that is known mainly for its nuts that are used as a food ingredient. Cashew gum interacts with water and it has emulsifier, adhesive and stabilizer properties, occurring in the form of pale yellow to reddish ambers. In cold water, it swells into a jelly like mass but dissolves rapidly when heated. The resin/gum secretory ducts that appear along the cashew tree bark were studied using histological procedures and microscopic observations. The gum was studied at its crude state and then chemically treated in order to obtain a kind of gel (microbiofilm).
\end{abstract}

Keywords: Cashew tree gum, Secretory ducts, Biosensor, Plant proteins.

\section{BIOMATERIALS}

Materials employed in biomedical technology are increasingly being designed to have specific, desirable biological interactions with their surroundings, rather than the older common practice of trying to adapt traditional materials to biomedical applications. Moreover, materials scientists are are capable to direct and control a desired biological response. Eventually, such bioengineered surfaces will become important tools to comprehend and analyze how materials interact in nature. Polymer hydrogels are either physically or covalently cross-linked polymer chains forming a highly water-swellable polymer network layer. Once the hydrogel is swollen in an aqueous environment, displacement of water

Table 1. Characteristics that Bioengineered Materials Share

\begin{tabular}{|l|l|}
\hline Characteristics & Comments \\
\hline \hline Self-assembly & $\begin{array}{l}\text { Bioengineered materials often rely on information content built into structural molecules to determine the } \\
\text { order and organization of the material. }\end{array}$ \\
\hline Hierarchical Structure & $\begin{array}{l}\text { In most bioengineered materials, several different lengths of scales of structure are essential and are formed } \\
\text { spontaneously and simultaneously via self-assembly. }\end{array}$ \\
\hline Precision Synthesis & Fundamental to biological material structures is the idea of macromolecules constructed in a precise manner. \\
\hline Templating & $\begin{array}{l}\text { Ordered structures in bioengineered materials are often propagated from one element, or set of instructions, to } \\
\text { another. }\end{array}$ \\
\hline Specific and Non-specific Interactions & The forces involved in holding biomaterials structures together are the specific and non-specific interactions. \\
\hline
\end{tabular}

also increasingly deriving new lessons from naturally occurring materials about useful composition structure property relationships that might be mimicked with synthetic materials. Together, these two areas of effort constitute "bioengineered materials" (Table 1).

In the future, a carefully selected combination of this set of characteristics will enable us to bioengineer surfaces that

\footnotetext{
*Address correspondence to this author at the Lectins and Glycoconjugates Laboratory, Dept of Biochemistry and Molecular Biology Federal University of Ceara, P.O. Box 6020, Fortaleza, Ceara, 60000, Brazil; Tel: +258 (21) 484 080; Fax: +258 (21) 485 819; E-mail: rmiranda@mz.pfscm.org "Present address: 2330 Maputo Place, Dulles, VA 20189-2330
}

molecules from the polymer layer is thermodynamically unfavorable. Thus, the strong interactions between water molecules and the polymer prevent attractive interactions between proteins and the hydrogel [1-6].

The self-association of water molecules in a threedimensional network driven by hydrogen bonds between the molecules is an important issue of materials in contact with biological fluids. The demand for fast, reliable and continuous measurements of chemical species in medicine, biotechnology and environmental sciences have evolved the need for small, easy to handle and inexpensive analytic devices. One key factor in biosensor construction is the development of immobilization technologies for stabilizing biomolecules 
and tethering them to surfaces. Cashew tree (Anacardium occidentale L.) resin is synthesized in the epithelial cells lining pockets or canals and then secreted into these internal cavities. Synthesis generally occurs in all organs of the plant, with different quantitative composition; appearing to be genetically controlled and little influenced by environmental conditions. The gum is similar to gum arabic and may be used as to a substitute for liquid glue for paper, in the pharmaceutical/cosmetic industry and as an agglutinant for capsules and pills $[1,2,7]$. Fifteen species of trees or perennial bushes compose the genus Anacardium, native of tropical parts of South America and Central and of western India [810].

The exudate gum is a mixture of acid polysaccharides containing various metal ions as neutralized cations. The nature and content of these constituents depend on the composition of the soil upon which the trees grew. The major cations of A.occidentale L. are $\mathrm{K}^{+}, \mathrm{Na}^{+}, \mathrm{Ca}^{+2}$ and $\mathrm{Mg}^{+2}$. The crude A.occidentale gum, containing these cations tends to be naturally transformed into $\mathrm{Na}$ salt, after purification or dialysis against $\mathrm{NaCl} 0,15 \mathrm{M}[2-4,7,8,11]$.

The cashew tree is a hardy, fast-growing, evergreen with an umbrella-like canopy. The tree has a rather messy look with its gnarled stem and crooked branches [7]. They are easily cultivated, vigorous, and drought-resistant, requiring little care. They may live for thirty or forty years [10, 12-14]. Cashew was probably originated in northeastern Brazil and was introduced to other countries in the sixteenth century [4]. It was "discovered" by Europeans and first recorded in 1578, and taken to India, then to East Africa where it soon became naturalized [14]. India is the present leader in cashew production, followed by Mozambique, Tanzania and then Brazil. Cashew trees produce both a fruit ("apple") nut and valuable oil that can be drawn from the nutshell. The nuts are 25-40 $\mathrm{mm}$ long and are covered with a hard shell.
The presence of phenolic resine $[13,14]$ is still a nuisance for harvesting and shelling. Although the fruit can be used for making many typical fruit products (jellies, jams, juice, wine and liquor), the apple is often discarded, in pursuit of the nut $[7,9]$.

The cashew nut must be roasted to remove the liquid that exists inside the shell. This liquid, known as caustic nutshell liquid (CNSL) [15] contains the poisonous cardol and anacardic acid [1, 13, 14]. Cashew is a multi-purpose tree of the Amazon, and is frequently found growing wildly on the drier sandy soils in the central plains of Brazil. It grows up to 15 meters in height and has a thick and tortuous trunk and branches so winding that they frequently reach the ground [1, 4, 16-18].

\section{MATERIAL AND METHODS}

\section{Histological Studies}

The bark secretory ducts were studied through tangential cuts that were made along the bark. The tissues' samples were submitted to histological procedures and microscopically observed optical microscope, as shown by Fig. (1).

\section{Gum Obtaining and Purification}

The gum sample was collected from trees (injury site) grown on the State of Ceará, Northeast coast of Brazil. Few details of the botanical aspects were noted. Sulphuric acid concentrations of $0,15,30$ and $45 \%$, combined with concentrations of $0,5,10,15$ and $20 \%$ of 2-chloroethylphosphonic acid and 5\% dimetil sulphoxide were tested in a factorial design. The influence of the stimulant over the future gum exudation was also assessed. A general increase of gum exudation was obtained in all months following the stimulant applications; sulphuric acid did not increase gum exudation in any of the used concentrations. Samples (Fig. 2) were ground to pass through a $2.5 \mathrm{~mm}$ sieve. Dried gum $(10 \mathrm{~g})$
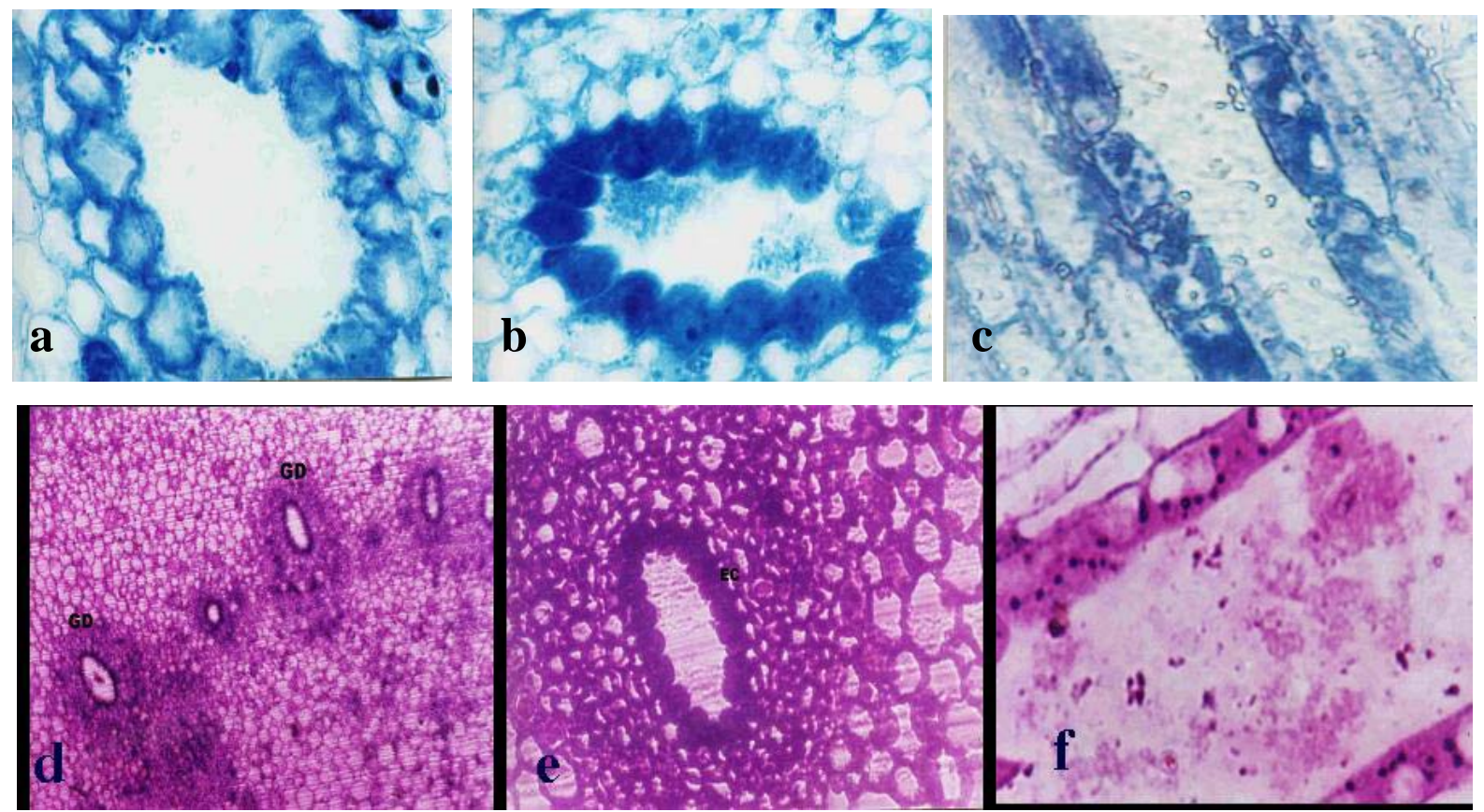

Fig. (1). Cashew-tree bark tissue samples were embedded in paraffin blocks, transversally sectioned (5 $\mu \mathrm{m}$ thick), placed onto glass slides and stained with toluidin blue (blue: $\mathbf{a}, \mathbf{b}$ and $\mathbf{c}$ ) or acid fucsin $1 \%$ (magenta: d, e and $\mathbf{f}$ ) in order to identify the nuclei, cell wall and carbohydrate secretion. (light optical microscopy, 200 - 400X). (GD: gum duct). 
was stirred in distilled water $(250 \mathrm{~mL})$ for $6-8$ hours at room temperature (RT). A supernatant was obtained by centrifugation. The residue was washed with water and the washing was added to the separated supernatant. The procedure was repeated four times more. The supernatant was made up to $500 \mathrm{~mL}$ and treated with ethanol $(1: 4 \mathrm{v} / \mathrm{v})$ in order to precipitate all the carbohydrates. The moisture was washed again with distilled water and freeze-dried. The cross-linking chemical treatment was done into alkaline $\mathrm{pH}(\mathrm{NaOH} 3,3 \mathrm{M})$, using epichlorohydrin 12,5 $\mathrm{N}$ (according to previous works $[1,4,9-11]$.

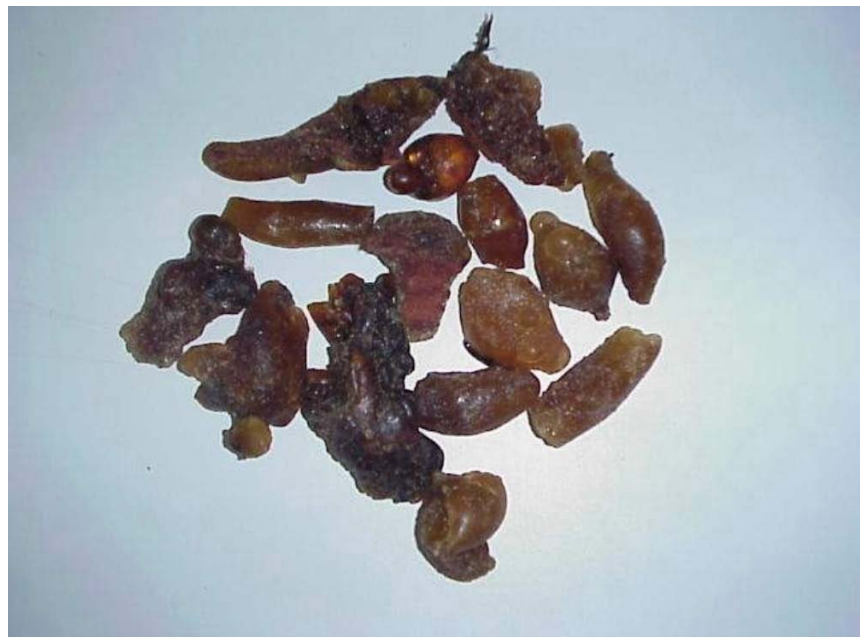

Fig. (2). Crude cashew-tree exudates samples, cleaned and free of insects or soil contamination. The resin, after being dissolved in distilled water was used for cross-linking procedures and further analysis.

\section{Insolubilization Gum Treatment with Epychlorohydrin}

Chromatographic columns ( $5 \mathrm{~mL}$ gel) were prepared with the obtained polysaccharides. To each $6 \mathrm{~g}$ of cashew tree gum $1,0 \mathrm{~mL}$ of epychlorohydrin $12.5 \mathrm{~N}$ and $8,0 \mathrm{~mL}$ of $\mathrm{NaOH} 5 \mathrm{M}$ were added. The mixture was shaken manually, maintained for 24 hours to $40{ }^{\circ} \mathrm{C}$ and for 12 hours to $70{ }^{\circ} \mathrm{C}$. After this period, the material was exhaustively washed with distilled water, until all the fine particles in suspension were removed. The material was homogenized and past in sieve of 30 meshes, being the fine particles removed by exhausting wash with distilled water.

\section{Protein-Biosensor Procedures}

In order to evaluate the cashew-gum's ability in retaining plant lectins, bioaffinity procedures were done, using the cross-linked polysaccharidic matrix, as described in a previous work [10].

\section{Bioaffinity Evaluation Procedures}

The chromatographic procedures were accomplished in 5 $\mathrm{mL}$ hypodermic syringes (Fig. 3). The columns were constructed leaving the gel $(0,3 \mathrm{~g})$ sedimentate itself by gravity and balanced with $\mathrm{NaCl} 0,15 \mathrm{M}$. Lectin-rich samples were applied and left in contact with the gel for 30 minutes. The elution initially was made with the same balance solution, followed by beta-alanine $(0.1 \mathrm{M}, \mathrm{pH} 2.6)$ elution (in $\mathrm{NaCl}$ $0.15 \mathrm{M} \mathrm{pH} 2.6$ ). The elution was accomplished to a constant flow and the obtained fractions had their absorbances determinated at $280 \mathrm{~nm}$.

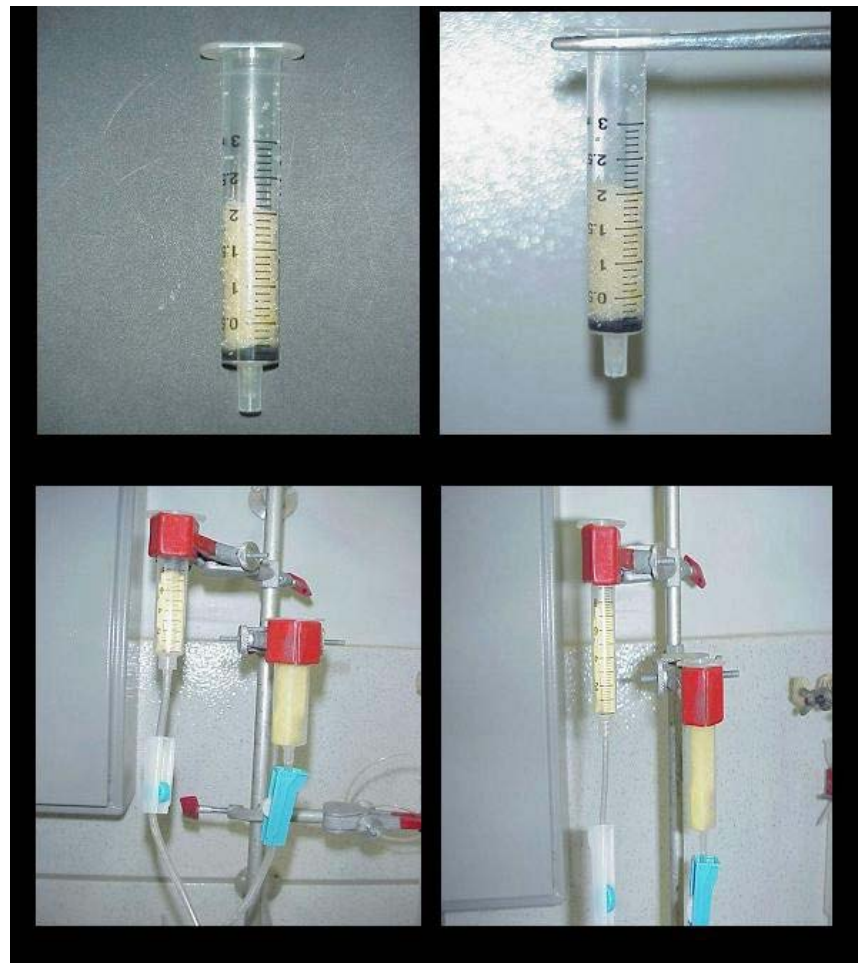

Fig. (3). Hypodermic syringes used to perform the affinity chromatographic assays, using the cross-linked (with epychlorohydrin $12.5 \mathrm{~N}$ ) cashew-tree exudates as the affinity matrix.

\section{RESULTS AND DISCUSSION}

\section{Cashew-Gum Chemical Characterization}

Cashew gum is a bark exudate of A.occidentale, a tree that grows wild in many tropical and subtropical countries. The elementary analysis revealed: humidity $(7,4 \%)$, total protein $(0,5 \%)$, total lipids $(0,06 \%)$, fibers $(0,95 \%)$ and ashes $(0,95 \%)$. According to previous work [16], the gum is a complex polysaccharide, comprising $61 \%$ galactose, $14 \%$ arabinose, $7 \%$ rhamnose, $8 \%$ glucose, $5 \%$ glucuronic acid and $<2 \%$ other sugar residues. It has a highly branched galactan framework consisting of chains of $(1 \rightarrow 3)$-linked $\beta$-dgalactopyranosyl units with interspersed $\beta(1 \rightarrow 6)$ linkages. The main aldobiouronic acid present is $6-\mathrm{O}-(\beta-\mathrm{D}-$ glucopyranosyluronic acid)-D-galactose. Its further characterization is desirable, with a view to incorporating it in porous films or beads in combination with other polysaccharides or proteins, which has been currently studied.

In dilute solutions of polymers, where molecules are widely separated, the viscosity showed slight shear rate dependence. Increasing polymer concentration, a stage is reached at which the polymer coils interpenetrate and the physical contact changes the flow behavior. In solutions of intermediate concentration, the viscosity is controlled pri- 
marily by the extent that the polymer chain interpenetrates, which can be characterized by the coil overlap parameter, $c[\eta]$; it indicates the volume occupied by the polymer molecule in the solution. The results regarding to cashew gum dispersion show thinning non-Newtonian flow behavior. If no intermolecular interaction occurs, the viscosity of the diluted gum solution decreases due the screening of charge and contraction of the macromolecule in the presence of counter-ion. In more concentrated solution, the presence of multivalent ions may promote interaction between chains and an increase in viscosity. As the gum concentration increases, the effect of the interaction between polysaccharide molecules over the reduced viscosity becomes predominant, reflected in changes in the Huggins viscosity slope parameter, $k_{\mathrm{H}}$. A little decrease of viscosity was observed for the solution at different gum concentrations. Because of the dispersion shear-thinning nature, the cashew gum should be suitable for application as a thickening agent or, even, it appears to be an interesting choice for biofilm matrix construction. It is possible to suggest the construction of a biofilm or bioidentification tool, using the cross-linked (insoluble) cashew-tree gum gel. This data support the idea of using cashew tree exudate gum as an efficient protein ligand (biological recognition, biosensor), stimulating future lectin identification or purification procedures. The use of natural gums, taken from the exudates and extracts of plants, has been given a strong impetus due to the many and lucrative possibilities for industrialization. This work brings a new perspective to using an inexpensive material, easily found along the Brazilian coast, the cashew-tree exudates gum. Studies on conductivity need to be done to evaluate the potential of the cashew-tree exudates gum as a biosensor for plant proteins. As well, the insolubilization treatment could be an useful tool to help transforming this natural gum into a useful instrument for glycobiotechnological studies.

\section{ACKNOWLEDGEMENTS}

This work was supported by the Brazilian Financial Institutions: FUNCAP, CNPq and CAPES.

\section{REFERENCES}

[1] Bovin NVG. Polyacrylamide-based glycoconjugates as tools in glycobiology. Glycoconjug J 1998; 15: 431-46.
[2] De Paula RCM, Healthy F, Budd PM. Characterisation of anacardium occidentale. exudate polysaccharide. Polym Int 1998; 45: 2735 .

[3] Caron M, Sève A-P, Bladier D, Joubert-Caron R. Glycoaffinity chromatography and biological recognition. J Chromat B 1998; 715: 153-61.

[4] León de Pinto G, Paz de Moncada N, Martinez M, Gutiérrez de Gotera O, Rivas C, Ocando E. The molecular characterization of the polysaccharide gum from Laguncularia racemosa. Biochem Syst Ecol 1994; 2: 291-5.

[5] Martinez M, León de Pinto G, Rivas C, Ocando E. Chemical and spectroscopic studies of the gum polysaccharide. from Acacia. Macracantha Carbohydr Polym 1996; 29: 247-52.

[6] Otani Y, Tabata Y, Ikada Y. Sealing effect of rapidly curable gelatin-poly (L-glutamic acid) hydrogel glue on lung air leak. Biomaterials 1996; 17: 1387-91.

[7] Amadeo GI, Moreira R, Lima R, Teixeira D, Kratje R, Etcheverrigaray M. Screening of lectins from South American plants used as affinity ligands to purify rhEPO. Braz J Chem Eng 2003; 20(1): 1-8.

[8] Carver J. Efficient carbohydrate release, purification and derivatization. Carbohydr Res 1997; 300: 1-2.

[9] León de Pinto G, Martinez M, Gutiérrez de Gotera O, Vera A, Rivas C, Ocando E. Comparison of two Pithecellobium gum exudates. Biochem Systs Ecol 1995; 23: 849-53.

[10] León de Pinto G, Martinez M, Ludovic de Corredor A, Rivas C, Ocando E. 1D- and 2D-NMR spectroscopy studies of the polysaccharide gum from Spondias purpurea var. lutea. Phytochemistry 1994; 37: 1311-5.

[11] Charlwood J, Birrell H, Camilleri P. Efficient carbohydrate release, purification and derivation. Anal Biochem 1998; 262: 197-200.

[12] Menestrina JM, Iacomini M, Jones C, Gorin PA. Similarity of monosaccharide, oligosaccharide and polysaccharide structures in gum exudate of Anacardium occidentale. Phytochemistry 1998; 47(5): 715-21.

[13] Tsurutani R, Yoshimura M, Tanimoto N, Kifune K. Chitosan oligosaccharide inhibits $\mathrm{HgCl}$-induced genotoxicity. Membrane 1995; 20: 255-62.

[14] Venning FD. A relationship between seed development, Arabinogalactan-proteins (AGPs) and the AGP mediated promotion of somatic embryogenesis. Am J Bot 1948; 35: 637-644.

[15] Schorsch C, Garnier C, Doublier JL. Phase separation in dextran /locust bean gum. Carbohydr Polym 1997; 34 (3): 165-75.

[16] Lima RSN, Lima JR, Salis CR, Moreira RA. Cashew- tree (Anacardium occidentale L.) exsudate gum: a novel bioligand tool. Biotechnol Appl Biochem 2002: 35: 47-53.

[17] Cordemoy HJ. Encyclopédie Scientifique. Academie des Sciences: Paris 1911

[18] Iqbal SS, Mayo MW, Bruno JG, Bronk BV, Batt CA, Chambers JP. A review of molecular recognition technologies for detection of biological threat agents. Biosens Bioelectron 2000; 15: 549-78. 